patients $(72.7 \%)$ and $60 / 103 \mathrm{mNY}$ - patients $(58.3 \%)$ had a positive MRISI (ASAS definition).

The table shows the mean scores for MRI-SI lesions. In erosions, fatty lesions and ankylosis, either partial or complete ankylosis, there was a statistically significant difference $(\mathrm{p}<0.05)$ between $\mathrm{mNY}+$ and $\mathrm{mNY}$ - patients.

Table:. Average MRI-SI lesion scores in axSpA patients with a symptom onset of $<30$ years fulfilling and not fulfilling the modified New York criteria.

\begin{tabular}{lccc}
\hline MRI lesions & $\mathbf{m N Y}+(\mathbf{n}=\mathbf{1 1})$ & $\mathbf{m N Y}-(\mathbf{n}=103)$ & P-value \\
\hline Inflammatory lesions (SPARCC score) $^{*}$ & $8.9( \pm 6.0)$ & $7.3( \pm 7.2)$ & 0.341 \\
Erosions* $^{*}$ & $7.6( \pm 4.4)$ & $3.5( \pm 4.2)$ & 0.003 \\
Fatty lesions* $^{*}$ Sclerosis* & $6.6( \pm 8.3)$ & $1.8( \pm 4.6)$ & 0.005 \\
(Partial) Ankylosis* $^{*}$ & $1.1( \pm 2.0)$ & $0.9( \pm 2.6)$ & 0.237 \\
\hline
\end{tabular}

${ }^{*}$ mean $( \pm \mathrm{SD})$

Conclusion: Patients with newly diagnosed axSpA and a symptom onset before 30 years infrequently fulfill the $\mathrm{mNY}$ criteria. A statistically significant difference in the presence of MRI-SI structural lesions was reported between $\mathrm{mNY}+$ and $\mathrm{mNY}$ - patients. AxSpA patients with an early symptom onset have more erosions, fatty lesions and ankylosis on MRI when fulfilling the mNY criteria.

Disclosure of Interests: Manouk de Hooge: None declared, Ann-Sophie De Craemer: None declared, Thomas Renson: None declared, Philippe Carron: None declared, Liselotte Deroo: None declared, Dirk Elewaut: None declared, Filip van den Bosch Consultant for: AbbVie, BMS, Galapagos, Janssen, Lilly, Merck, Novartis, Pfizer and UCB, Speakers bureau: AbbVie, BMS, Janssen, Lilly, Merck, Novartis, Pfizer and UCB.

DOI: 10.1136/annrheumdis-2019-eular.7464

\section{SAT0323 HEPATOCYTE GROWTH FACTOR IS A PREDICTOR OF DEVELOPMENT OF NEW SYNDESMOPHYTES IN MEN WITH ANKYLOSING SPONDYLITIS. A FIVE YEAR PROSPECTIVE STUDY}

$\underline{\text { Anna Deminger }}{ }^{1}$, Eva Klingberg ${ }^{1}$, Merja Nurkkala ${ }^{1}$, Hans Carlsten ${ }^{1}$, Lennart T. H. Jacobsson ${ }^{1}$, Helena Forsblad-D'elia ${ }^{1,2}$. ${ }^{1}$ Sahlgrenska Academy at University of Gothenburg, Department of Rheumatology and Inflammation Research, Göteborg, Sweden; ${ }^{2}$ Deparment of Public Health and Clinical Medicine, Rheumatolgy, Umeå University, Umeå, Sweden

Background: Patients with ankylosing spondylitis (AS) have an increased risk of spinal new bone formation characterized by the development of syndesmophytes. Knowledge of predictors for development of syndesmophytes is limited. Hepatocyte growth factor (HGF) has regulatory effects on a variety of cells in many different organs. HGF signaling can affect both osteoclast and osteoblast lineages and has been shown to promote osteogenesis. Cross-sectional association between increased HGF and increased modified Stoke Ankylosing Spine Score (mSASSS) has previously been shown [1], whereas knowledge of HGF as a predictor for new bone formation is lacking.

Objectives: To study serum HGF as a predictor for development of new syndesmophytes in patients with AS followed for five years.

Methods: Serum levels of HGF was analyzed using ELISA in patients with AS (modified NY-criteria) and in healthy controls $(\mathrm{HC})$ at baseline. Spinal lateral radiographs were obtained at baseline and at the 5-year follow-up and assessed for development of new syndesmophytes using mSASSS. Univariate and multivariable logistic regression analyses were used to assess predictors for development of $\geq 1$ new syndesmophyte. Results: Serum HGF and radiographs at baseline and follow-up were available for 163 patients, 88 men and 75 women, baseline mean age $50 \pm 12$ years. AS patients had higher serum HGF than HC $(n=80)$, $\mathrm{p}=0.050$. In the AS group, 36 patients (22\%) developed $\geq 1$ syndesmophyte, 27 men and 9 women. In the total AS group, neither did baseline serum HGF differ between those who developed $\geq 1$ new syndesmophyte and those who did not progress, nor did it predict development of $\geq 1$ new syndesmophyte in the univariate analysis, $p=0.25$. Interestingly, men who developed $\geq 1$ new syndesmophyte had higher serum HGF than the non-progressors $(1706 \pm 454$ vs $1420 \pm 338 \mathrm{pg} / \mathrm{mL}, \mathrm{p}=0.001)$ and increased serum HGF at baseline predicted development of $\geq 1$ syndesmophyte (OR per $1 \mathrm{SD}$ HGF $2.39,95 \% \mathrm{Cl} 1.31$ to 4.36 ) in the univariate analysis. Serum HGF did not predict new syndesmophytes in women, $\mathrm{p}=0.13$. Multivariable analysis for men including age, smoking, baseline syndesmophyte and serum HGF showed high HGF (OR per 1SD 1.90, $95 \% \mathrm{Cl} 1.01$ to 3.59 ) and $\geq 1$ baseline syndesmophyte (OR 3.48 , 95\% $\mathrm{Cl} 1.09$ to 11.07 ) to independently predict development of $\geq 1$ new syndesmophyte. If baseline CRP was included in the multivariable model, serum HGF and baseline syndesmophytes remained the significant predictors.

Conclusion: High baseline serum HGF was shown to independently predict the development of at least one new syndesmophyte over five years in men with AS.

\section{REFERENCE}

[1] Torres L, Klingberg E, Nurkkala M, Carlsten H, Forsblad-d'Elia H. Hepatocyte growth factor is a potential biomarker for osteoproliferation and osteoporosis in ankylosing spondylitis. Osteoporos Int 2018.

Disclosure of Interests: Anna Deminger: None declared, Eva Klingberg Grant/research support from: Unrestricted grant from Roche, Consultant for: Novartis, Speakers bureau: Speakers fee from Lilly, Merja Nurkkala: None declared, Hans Carlsten: None declared, Lennart T.H. Jacobsson Consultant for: LJ has received lecture and consulting fees from Pfizer Abbvie, Novartis, Eli-Lily and Janssen, Helena Forsblad-d'Elia Grant/ research support from: Unrestricted grants from Novartis outside the submitted work, Consultant for: Advisory board fees from Sandoz, Novartis and Abbvie, Speakers bureau: Lecturing fees from Novartis DOI: 10.1136/annrheumdis-2019-eular.4559

\section{SAT0324 ARTICULAR MANIFESTATIONS IN PATIENTS WITH INFLAMMATORY BOWEL DISEASE TREATED WITH VEDOLIZUMAB}

Anastasia Dupré $^{* 1}$, Michael Collins ${ }^{1}$, Franck Carbonnel ${ }^{1}$, Xavier Mariette $^{1}$, Gaetane Nocturne', Raphaèle Seror ${ }^{1}{ }^{1}$ Bicetre Hospital AP-HP, Le KremlinBicêtre, France

Background: Vedolizumab (VDZ) is a humanized IgG1 monoclonal antibody anti- $\alpha 4 \beta 7$ integrin agent used in inflammatory bowel disease (IBD). It has been incriminated in occurrence of articular manifestations but, as it is given in most cases after anti-TNFÎ \pm therapy, it is not known if these articular manifestations are linked to IBD-associated arthritis and unmasked by withdrawal of anti-TNFÎ or are more directly linked to VDZ.

Objectives: The purpose of this study is to describe articular manifestations occurring in patients treated by vedolizumab, and to highlight risk factors for inflammatory manifestations.

Methods: In this retrospective monocentric study, we collected all the cases of incident articular manifestations occurring in the follow-up of the patients treated by VDZ for IBD.

Results: Between February 2013 and June 2017, 112 patients were treated withvedolizumab (56 women, age $39.9 \pm 16$ years, disease duration $=9.1 \pm 7.8$ years $)$. IBD cases were distributed into59 $(52.7 \%)$ Ulcerative Colitis (UC), 49 (43.8\%) Crohn's disease (CD), and 4 (3.6\%) Undetermined Colitis. Fourpatients (3.6\%) had a history of spondyloarthritis and $13(11.6 \%)$ of peripheral arthralgia associated with IBD. 102 $(91.1 \%)$ patients previously received anti-TNF $\alpha$. At initiation of vedolizumab, $55(49.1 \%)$ received an associated DMARD (azathioprine in 19.6\%, purinethol in $11.6 \%$, methotrexate in $7.1 \%$ ).

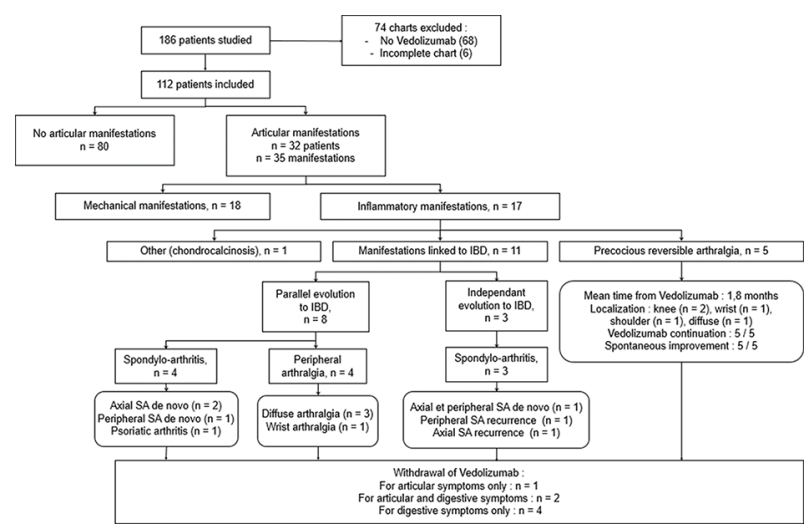

After a mean follow up duration of $11.4 \pm 8.6$ months, 32 (28.6\%) patients presented 35 types of articular manifestations, mechanical $(\mathrm{n}=$ 18) (mostly osteoarthritis and tendinitis)or inflammatory ( $n=17$ ). Inflammatory articular manifestations were: early reversible arthralgia mostly occurring during perfusion $(n=5)$, manifestations linked to IBD $(n=11$, axial spondyloarthritis, $\mathrm{n}=3$, peripheral spondyloarthritis, $\mathrm{n}=3$, 